\title{
PLEUROSKOPI SEBAGAI TINDAKAN DIAGNOSTIK PADA PARU
}

\author{
Hafis Herdiman ${ }^{1}$, Oea Khairsyaf ${ }^{1}$, Russilawati Russilawati ${ }^{1}$ \\ ${ }^{1}$ Bagian Pulmonologi dan Kedokteran Respirasi Fakultas Kedokteran Universitas \\ Andalas, RSUP Dr. M. Djamil Padang
}

\begin{abstract}
Pleuroscopy, also known as medical thoracoscopy, is a minimally invasive procedure that is used to examine and biopsy the pleural cavity as well as to perform therapeutic interventions. This procedure has a near-perfect diagnostic accuracy in malignant pleural effusions and tuberculosis. With a mortality rate of $0.1 \%$, the complication rate is low $(2 \%$ $5 \%$ ) and usually mild (subcutaneous emphysema, bleeding, infection). Objective : Increase knowledge of pleuroscopy as a diagnostic and therapeutic tool in lung disease. Method : This paper is based on a review of the literature on pleuroscopy. Conclusion : Pleuroscopy is a minimally invasive procedure that can be used to examine and biopsy the pleural cavity, as well as for therapeutic intervention. Complications are uncommon and usually minor.

Sugestion : Other articles are required to increase knowledge about pleuroscopy in order to obtain more knowledge.
\end{abstract}

Keyword : pleuroscopy; medical thoracoscopy; diagnostic

\begin{abstract}
Abstrak
Pleuroskopi, juga dikenal sebagai torakoskopi medis, adalah prosedur invasif minimal untuk memeriksa dan melakukan biopsi rongga pleura serta melakukan intervensi terapeutik.. Akurasi diagnostik dari prosedur ini mendekati 100\% pada efusi pleura ganas dan tuberculosis. Tingkat komplikasi rendah (2\% -5\%) dan biasanya ringan (emfisema subkutan, perdarahan, infeksi), dengan angka kematian 0,1\%. Tujuan : Menambah wawasan mengenai pleuroskopi sebagai tindakan diagnostik dan terapeutik pada penyakit paru terutama kelainan di rongga pleura. Metode : Tulisan ini berasal dari berbagai literatur yang disusun dan terkait dengan pleuroskopi. Kesimpulan: Pleuroskopi adalah tindakan prosedur invasif minimal untuk memeriksa dan melakukan biopsi pada rongga pleura, serta dapat juga untuk tindakan intervensi terapeutik. Tingkat komplikasi rendah, dan biasanya ringan. Saran : Diperlukan artikel lainnya untuk menambah pengetahuan tentang pleuroskopi, agar pengetahuan yang didapat lebih banyak.
\end{abstract}

Kata kunci: pleuroskopi; torakoskopi medis; diagnostik

\section{PENDAHULUAN}

Pleuroskopi sudah dikenal lebih dari 100 tahun yang lalu. Dalam 40 tahun belakangan, pleuroskopi digunakan dalam pengobatan pneumotoraks tuberkulosis terutama pada kasus pleuro-pulmonal adhesis yang mencegah kolaps paru. Pada tahun 1950-an, pengobatan pneumotoraks tuberkulosis berakhir dan pleuroskopi digunakan di beberapa pusat oleh dokter sebagai metode diagnostik dan terapeutik pada beberapa penyakit paru. Pada 1990an, ahli bedah toraks memperkenalkan teknik untuk operasi invasif minimal, yang dikenal sebagai "surgical thoracoscopy" atau "video-assisted thoracic surgery" (VATS), yang dilakukan di bawah anestesi umum dengan ventilasi satu paru. Saat ini, pleuroskopi 
semakin banyak digunakan, terutama pada pasien dengan efusi atau pneumotoraks, termasuk talc poudrage sebagai pleurodesis konservatif terbaik. ${ }^{1}$

Pleuroskopi, juga dikenal sebagai torakoskopi medis, adalah prosedur yang digunakan untuk memvisualisasikan dan mengevaluasi ruang pleura dan melakukan pleurodesis atau intervensi terapeutik lainnya. Pleuroskopi berbeda dari video-assisted thoracic surgery (VATS) dalam beberapa hal. Biasanya dilakukan dengan sedasi dan pasien bernapas secara spontan selama prosedur dilakukan. Pasien tidak menjalani ventilasi paru tunggal dengan tabung endotrakeal dual-lumen selama pleuroskopi, tetapi paru ipsilateral mengempis secara pasif untuk memungkinkan inspeksi penuh ruang pleura. Pleuroskopi dilakukan melalui satu atau dua port berbeda dengan dua hingga empat port yang digunakan dalam VATS. Pleuroskopi/torakoskopi medis dilakukan oleh non-ahli bedah di ruang non-operasi (misalnya, unit endoskopi) dengan anestesi lokal dan sedasi. Sedangkan, prosedur VATS dibantu oleh video yang bersifat lebih invasif dan dilakukan oleh ahli bedah di ruang operasi dengan anestesi umum., ${ }^{2,3}$

Langkah-langkah utama yang dilakukan selama pleuroskopi meliputi persiapan pasien, aspirasi cairan, induksi pneumotoraks, anestesi lokal dan sedasi (jika ada), pengenalan trocar, penilaian rongga dada melalui pleuroskop menggunakan fotografi atau video, dan mengambil beberapa sampel biopsi diikuti dengan mengontrol perdarahan. Sensitivitas pleuroskopi dilaporkan berkisar antara 90 hingga 100\%. Pleuroskopi medis dapat dilakukan melalui instrumen rigid atau semi-rigid (flexi-rigid). Komplikasi utama yang dilaporkan pada prosedur pleuroskopi termasuk prolonged air-leak, perdarahan, dan empiema. Sedangkan, komplikasi ringan akibat pleuroskopi dapat mencakup emfisema subkutan, infeksi luka, demam, hipotensi, dan aritmia jantung. ${ }^{2,3}$

\section{METODE PENELITIAN}

Penelitian ini merupakan suatu artikel review yang mengulas beberapa kepustakaan terkini terkait pleuroskopi sebagai tindakan diagnosis pada paru. Rencana kegiatan adalah dengan mengumpulkan beberapa literatur,sedangkan cara pengumpulan datanya berasal dari beberapa literatur yang terkait dengan pleuroskopi sebagai tindakan diagnostik dan terapeutik pada penyakit paru.

\section{HASIL}

Definisi

Torakoskopi adalah prosedur yang melibatkan akses ke rongga pleura dengan endoskop dan memungkinkan visualisasi langsung dari rongga pleura dan struktur intratorakal untuk memperoleh jaringan atau melakukan intervensi di bawah bimbingan visual langsung. Torakoskopi secara luas dibagi menjadi torakoskopi medis invasif minimal (MT) dan torakoskopi bedah/ "'video-assisted thoracic surgery" (VATS). Pertumbuhan pesat 
pada bidang pulmonologi intervensi bersama denganevolusi teknik sedasi dan pengembanganflex-rigid thoracoscopes telah membawa MT ke garis depan.

Video-assisted thoracic surgery (VATS) mengacu pada prosedur thoracoscopic yang dilakukan di ruang operasi menggunakan ventilasi paru tunggal dengan intubasi endotrakeal lumen ganda dan berbagai instrumen sekali pakai. Secara teknis, setiap prosedur yang mencakup biopsi pleura parietal, drainase efusi pleura atau empiema, dan pleurodesis dilakukan dengan pasien di bawah anestesi umum.VATS diindikasikan untuk biopsi paru dengan stapler, reseksi nodul paru, lobektomi, pneumonektomi, pericardial window, atau standar lainnya pada prosedur bedah toraks yang dilakukan dengan cara invasi minimal.

Pleuroskopi dan VATS dapat dibedakan dalam beberapa hal terkait prosedur pelaksanaan, termasuk fasilitas, operator, dan anestesi yang digunakan. Pleuroskopi umumnya dilakukan pada kasus ekplorasi rongga pleura, biopsi pleura parietal, pleurodesis, dan penempatan chest tube dengan bantuan visualisasi. Sedangkan VATS dilakukan pada kasus lobektomi, pneumonektomi, reseksi nodul paru, stapled lung biopsy, dan beberapa kasus lainnya. ${ }^{4}$

\section{Alat}

Pleuroskopi dilakukan dengan menggunakan berbagai instrument dan alat sekali pakai untuk masuk ke dalam rongga pleura. Pleuroskopi umumnya dilakukan dengan teknik tusukan tunggal, memungkinkan operator untuk memvisualisasikan isi rongga pleura dan memasukkan instrumen aksesori dari pleuroskop rigid atau semi-rigid. Teknik tusukan ganda dapat dibuat di sepanjang ruang interkostal lain, memungkinkan penyisipan trocar pleural berukuran 3-10 mm untuk instrumen aksesori. Teknik ini sering digunakan untuk mengontrol perdarahan, memutuskan perlengketan, menyedot sejumlah besar cairan pleura, atau melakukan tindakan biopsi. ${ }^{4,5}$

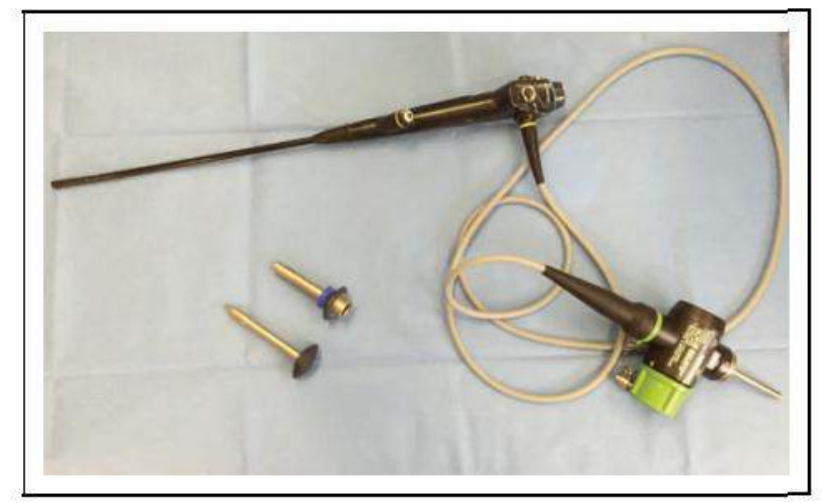

Gambar 1. Flex-rigid Thoracoscope

Dikutip dari (4) 


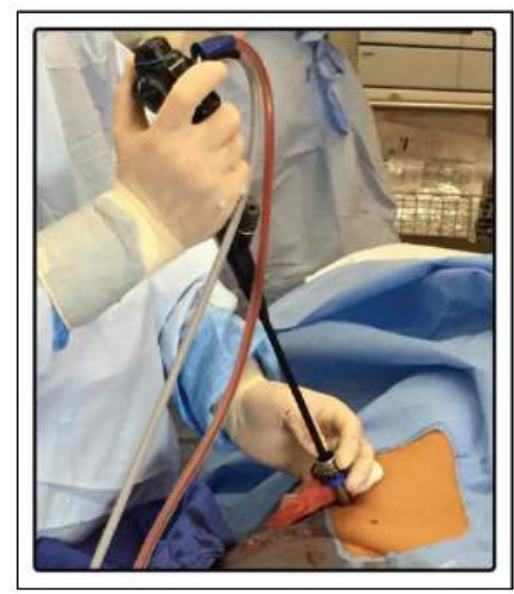

Gambar 2.Thoracoscope pada rongga pleura menggunakan trocar

Dikutip dari (4)

\section{Indikasi}

McCarty et al. membagi indikasi pleuroskopi ke dalam dua kelompok. ${ }^{6}$

\section{Indikasi Diagnostik}

Indikasi paling umum untuk pleuroskopi adalah pengambilan sampel efusi pleura eksudatif dengan etiologi yang tidak diketahui, karena memungkinkan visualisasi langsung dari rongga pleura dan biopsi langsung dari pleura abnormal. Di negara maju di mana insiden tuberkulosis rendah, $>50$ efusi pleura yang tidak terdiagnosis akan ditemukan maligna, terutama bila besar atau berdarah. Dalam kasus efusi pleura yang tidak dapat dijelaskan dengan analisis cairan pleura non-diagnostik dari torakosentesis, pleuroskopi merupakan indikasi mutlak.Selain mendiagnosis efusi maligna atau infeksi, pleuroskopi juga dapat digunakan untuk melakukan biopsi berbasis pleura, yang memungkinkan penentuan stadium kanker paru primer atau mesothelioma, serta flow cytometry, penanda tumor, dan analisis genetik.

\section{Indikasi Terapeutik}

Pleurodesis pleuroskopi adalah salah satu dari beberapa pilihan dalam pengelolaan efusi pleura ganas berulang yang cepat terakumulasi kembali. Agen sklerosis yang paling umum adalah talc poudrage, yang telah terbukti lebih berhasil dalam mencapai pleurodesis dibandingkan dengan bleomisin dan tetrasiklin.

\section{Kontraindikasi}

Pleuroskopi umumnya merupakan prosedur yang aman dan dapat ditoleransi dengan baik. Kontraindikasi absolut untuk pleuroskopi adalah penyempitan total rongga pleura karena perlengketan atau penyakit pleura; namun pada beberapa kasus hal ini dapat diatasi dengan memperluas insisi dan/atau diseksi tumpul pada perlengketan atau jaringan paru dari dinding dada. Kontraindikasi relatif untuk pleuroskopi adalah ketidakmampuan pasien 
untuk mentolerir posisi dekubitus lateral atau pneumotoraks yang diinduksi, status pernapasan yang lemah/hipoksia, ketidakstabilan kardiopulmoner, diatesis perdarahan atau koagulopati, atau alergi terhadap salah satu obat yang diperlukan. ${ }^{6}$

\section{PEMBAHASAN}

\section{Prosedur}

Prosedur dilakukan pada kondisi pasien berbaring ke sisi yang sehat dengan posisi dekubitus lateral. Titik masuk aksila pada garis midaxillary ruang intercostal empat-lima. Tumor metastatik atau difus mesothelioma maligna sering ditemukan pada sudut costovertebral inferior dan permukaan diafragma, sehingga entri yang disarankan adalah ruang intercostal lima-tujuh. Dalam kasus yang tidak biasa, titik masuk lain dapat digunakan tergantung pada pengaturan klinis dan/atau radiografi thoraks, computed tomography, dan hasil USG. Misalnya ruang interkostal anterior kedua-ketiga dipilih dalam kasus pneumotoraks ketika dicurigai blebs anterior atau superior. Sedasi yang umum digunakan adalah propofol dan midazolam, bersama dengan opioid untuk analgesia dalam persiapan untuk pleuroskopi. ${ }^{5,7}$ Prosedur yang disarankan pada pleuroskopi yaitu ${ }^{7}$ :

a. Pasien ditempatkan pada posisi dekubitus lateral dengan lokasi prosedur menghadap ke atas.

b. Periksa rongga pleura dengan USG mulai dari ruang interkostal ke-5 atau ke-6 di garis mid-aksila. Jika tidak melihat tanda sliding lung dan seashore, atau jika terdapat adhesi, pindah ke area yang berdekatan.

c. Setelah titik masuk ditentukan, bius pasien dengan lidokain $1 \%$ di bawah bimbingan USG. Perhatikan apakah lidokain telah menyusup ke ruang subkutan, lapisan otot dan pleura parietal.

d. Ujung tumpul trochar boutin dimasukkan ke dalam rongga pleura. Hal ini memungkinkan udara masuk ke rongga pleura, menciptakan pneumotoraks buatan dan kolaps paru. (Pada pasien dengan jumlah efusi pleura yang berlebihan, langkah ini dapat dilewati).

e. Dibuat insisi 1-2 cm, dan diseksi tumpul menggunakan forsep arteri dilakukan melalui jaringan subkutan, otot interkostal dan ke dalam rongga pleura.

f. Trochar $8 \mathrm{~mm}$ sekali pakai kemudian dimasukkan ke dalam rongga pleura, untuk lewatnya torakoskop.

g. Ruang pleura diperiksa, dan 6-8 biopsi diambil menggunakan forsep, dengan "lift and peel technique" 
h. Pada akhir prosedur, kateter pigtail 10-14 Fr ditempatkan ke dalam rongga pleura, yang memungkinkan evakuasi pneumotoraks. Sebaliknya, jika rencananya adalah memasang kateter pleura menetap (IPC) untuk drainase jangka panjang, maka IPC yang sama juga dapat memungkinkan drainase udara.

i. Setelah prosedur dilakukan rontgen dada portable.

j. Setelah paru mengembang kembali, kateter pigtail dapat dilepas.

\section{Komplikasi}

Komplikasi pleuroskopi secara umum, yang terjadi adalah prolonged air leak, perdarahan, emfisema subkutan, demam postoperative, empyema, infeksi luka, aritmia jantung, hipotensi, dan mesothelioma. ${ }^{4}$

\section{Aplikasi Klinis Pleuroskopi}

Pleuroskopi saat ini dapat diterapkan sebagai prosedur diagnostik dan tujuan terapeutik. Pleuroskopi juga dianggap sebagai salah satu bidang utama pulmonologi intervensi. ${ }^{1}$

\section{Efusi Pleura}

Pasien dengan gangguan pleura mungkin memerlukan evakuasi cairan pleura, biopsi pleura parietal, biopsi paru, atau pleurodesis. Torakoskopi medis/pleuroskopi memiliki peran utama dalam diagnosis invasif pada efusi pleura yang belum diketahui dan dalam pengobatan lokal. ${ }^{1}$ Keuntungan dari thorakoskopi medis/pleuroskopi dalam diagnosis efusi pleura adalah diagnosis yang cepat. Keuntungan lain yaitu biopsi yang tidak hanya dilakukan pada pleura dinding dada tetapi juga dari diafragma, paru dan mediastinum, dapat menentukan stadium pada kanker paru dan difus mesothelioma, dan mengeksklusi keganasan pada tuberkulosis dengan probabilitas tinggi. Pleuroskopi dianggap sebagai standar emas untuk studi ilmiah pada efusi pleura. Kelebihan dalam pengobatan efusi pleura adalah pengeluaran cairan segera (bahkan sampai beberapa liter), evaluasi lokulasi (TB, empiema), evaluasi mikroskopis potensi reekspansi paru dan talc poudrage untuk pleurodesis dengan distribusi talc seragam di bawah kontrol visual. ${ }^{1}$

Pada efusi pleura yang tidak diketahui, langkah pertama untuk menyelidikinya adalah thoracentesis.Cairan pleura dianalisis secara kimia, mikrobiologi, dan sitologi. Lebih dari setengah efusi eksudatif disebabkan keganasan, dan sitologi cairan pleura adalah metode definitif yang paling sederhana, namun hasil diagnostiknya tergantung pada luasnya penyakit dan sifat keganasan primer. Pemeriksaan sitologi cairan pleura merupakan diagnostic pada $62 \%$ kasus pleural metastasis dan $20 \%$ kasus mesothelioma. $^{8}$

\section{Kanker Paru}

Gambaran yang umum ditemukan pada adenokarsinoma paru adalah lokal deposit.Efusi pleura terkait kanker terjadi sebagai akibat dari invasi tumor langsung, emboli tumor ke pleura viseral dengan penyemaian sekunder pleura parietal, penyebaran hematogen, atau 
keterlibatan limfatik.Jarang ditemukan kanker paru yang dapat direseksi dalam kondisi efusi pleura meskipun pemeriksaan sitologi negatif. Oleh karena itu, pleuroskopi dapat menetapkan kelayakan operasi dengan menentukan apakah efusi pleura adalah paramaligna atau disebabkan oleh metastasis. $^{8}$

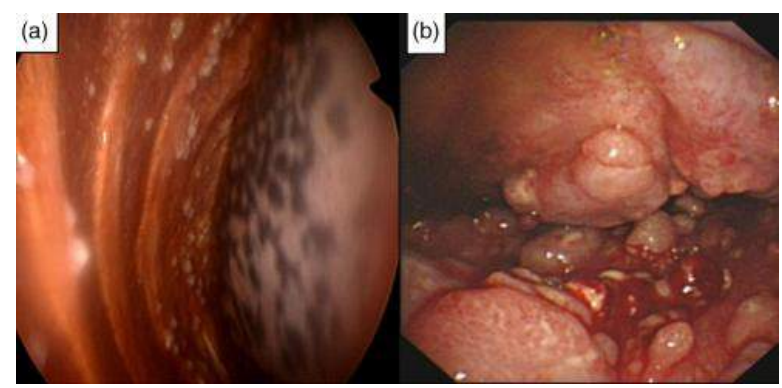

Gambar 3. Patological diagnosis pada Adenokarsinoma Paru

Dikutip dari (9)

\section{Mesothelioma Ganas}

Mesothelioma adalah neoplasma dengan insiden tinggi dan prognosis yang buruk.Diagnosis mesothelioma sulit dilakukan dengan sitologi dan biopsi tertutup.Pleuroskopi adalah metode terbaik untuk mendiagnosis tumor, dengan tingkat keberhasilan diagnosis $>90 \%$. Pada pemeriksaan akan ditemukan peningkatan proliferasi sel mesothelial pada rongga pleura. ${ }^{10}$

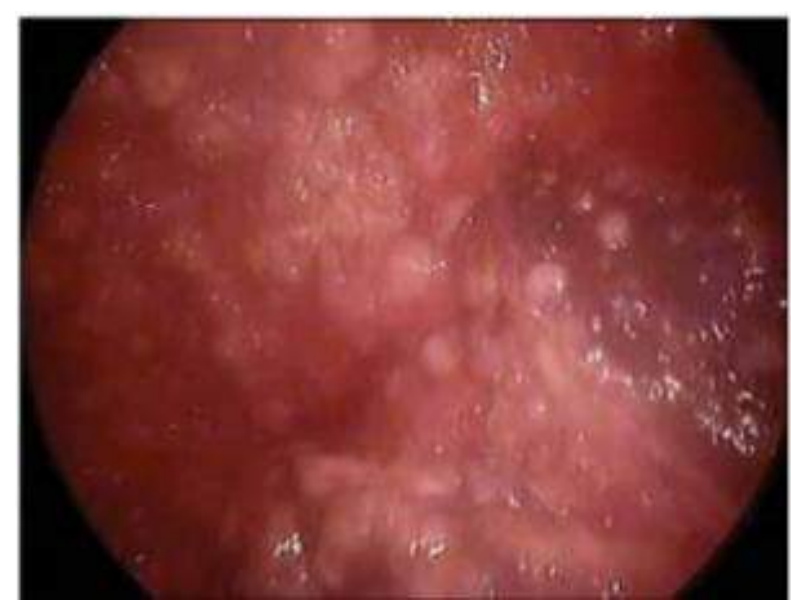

Gambar 4. Mesothelioma Epiteloid pada Rongga Pleura

Dikutip dari (10) 


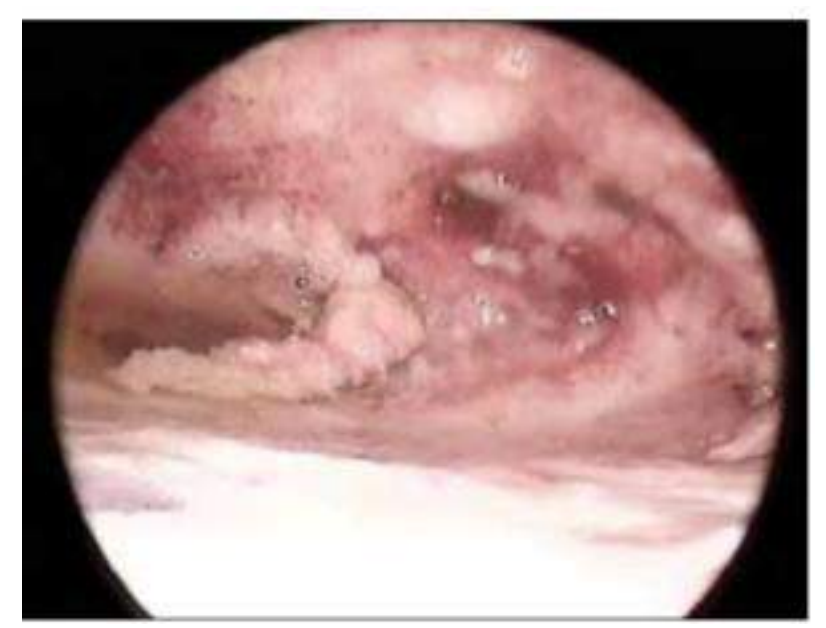

Gambar 5. Mesothelioma Sarcomatoid pada Rongga Pleura

Dikutip dari (10)

\section{Tuberkulosis}

Berdasarkan penelitian oleh Lee et al. ditemukan bahwa pada pasien TB yang dilakukan pemeriksaan pleuroskopi terdapat nodul halus difus, yang digambarkan sebagai "sago nodules". Hasil diagnostik rata-rata dari biopsi jarum tertutup pada efusi pleura tuberkulosis (TB) adalah 69\%.Dalam sebuah studi prospektif dari 100 orang dengan efusi TB di Jerman, diagnosis histologis ditegakkan dengan pleuroskopi (94\%) dibandingkan dengan biopsi jarum tertutup (38\%). Hasil positif dari kultur histologi dan bakteriologis juga ditemukan lebih tinggi dengan biopsi terpandu pleuroskopi dibandingkan dengan biopsi jarum tertutup dan gabungan cairan pleura. ${ }^{11}$

Prevalensi TB dengan diagnostik pleuroskopi biopsi terpandu adalah 98\%. Oleh karena itu, banyak ahli merekomendasikan diagnosis pada kasus curiga TB pleuritis, thoracentesis dan biopsi jarum tertutup harus ada, dan pleuroskopi harus tersedia pada keadaan khusus di mana lisis adhesi diindikasikan untuk drainase efusi yang lebih efektif atau bila jumlah jaringan yang diperlukan untuk kultur lebih besar di tempat yang dicurigai kasus resisten obat. Pleuroskopi memberikan hasil diagnostik yang tinggi dalam hal diagnosis pleuritis TB dan jenis pleuritis lainnya. ${ }^{12,13}$

\section{Pneumotoraks}

Pleuroskopi pada pneumotoraks spontan, dapat ditemukan blebs dan bula. Selain itu, juga memungkinkan koagulasi blebs, dan mencegah kekambuhan dengan metode seperti abrasi pleura atau talc pleurodesis. ${ }^{14}$ 


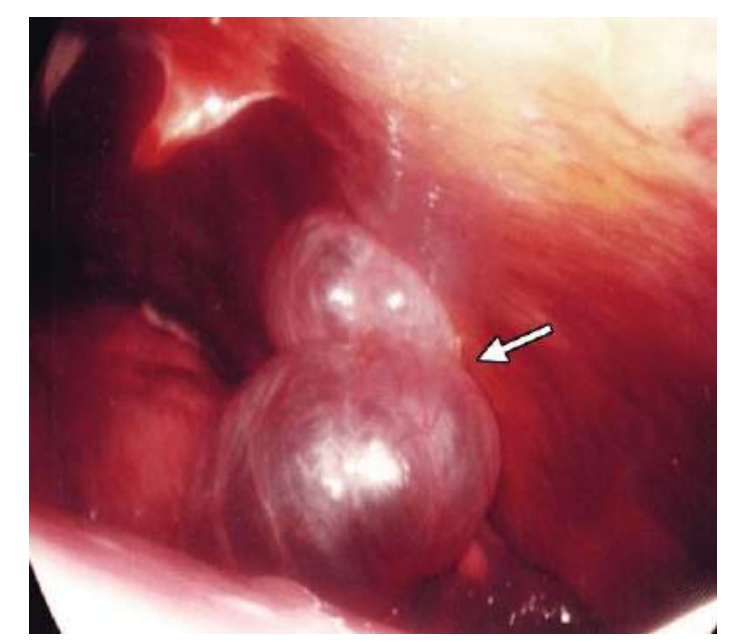

Gambar 6. Blebs pada Pasien dengan Pneumothoraks

Dikutip dari (11)

\section{Empiema Pleura}

Empiema didefinisikan sebagai akumulasi nanah di rongga pleura, terkait dengan morbiditas dan mortalitas yang signifikan pada orang dewasa dan anak-anak. Empiema dibagi menjadi tiga tahap, yaitu: tahap 1 ditemukan cairan pleura yang bergerak bebas (eksudatif), tahap 2 terdapat fibrino-purulen di mana fibrin menumpuk di permukaan pleura dengan cairan keruh dan kental yang cenderung terlokulasi, dan tahap 3 merupakan penebalan fibrosa dari pleura visceral yang mengarah ke trapped lung oleh adhesi fibrosa pada pleura. USG dan CT scan dapat memvisualisasikan septasi dan lokulasi dalam empiema. Pleuroskopi umumnya digunakan untuk prosedur drainase. ${ }^{15}$

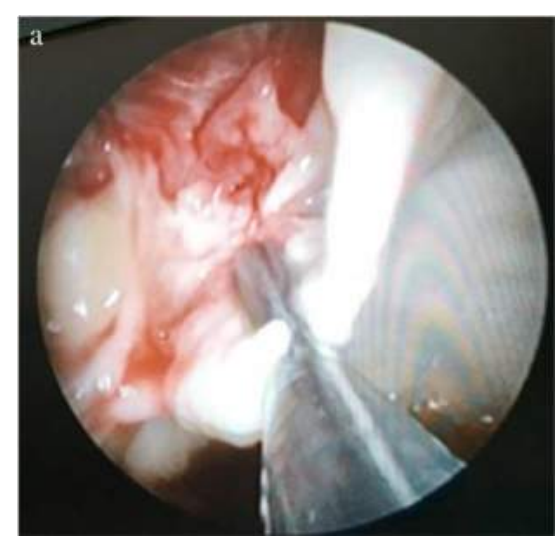

Gambar 7. Empiema loculated tebal pada Pleuroskopi

Dikutip dari (14) 


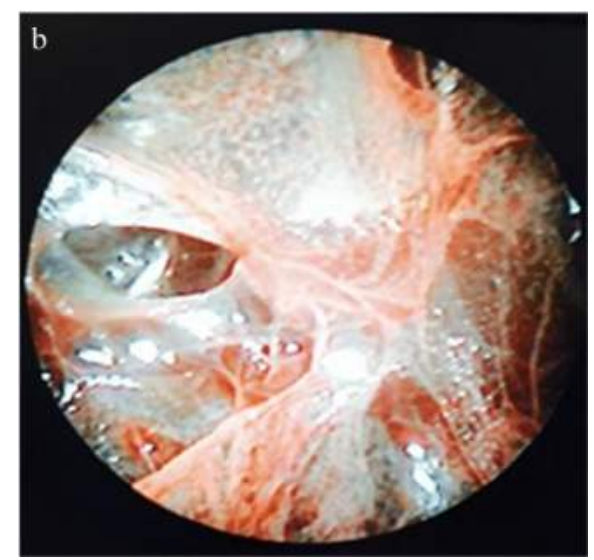

Gambar 8. Membran Fibrin pada Rongga Pleura

Dikutip dari (14)

\section{KESIMPULAN}

Pleuroskopi efektif dalam evaluasi pleura dan penyakit paru.Pleuroskopi juga memiliki akurasi tinggi dalam diagnosis.Selain diagnosis, pleuroskopi dapat melakukan terapi intervensi pada empiema, efusi pleura ganas berulang, dan pneumotoraks. Pleuroskopi memiliki profil keamanan yang baik dengan tingkat komplikasi keseluruhan untuk torakoskopi adalah 1-5\% dan tingkat kematian kasus 0,8\%. Disarankan artikel lainnya untuk menambah pengetahuan tentang pleuroskopi, agar pengetahuan yang didapat lebih banyak.

\section{DAFTAR PUSTAKA}

1. Lee P, Noppen M. History and clinical use of thoracoscopy / pleuroscopy in respiratory medicine. Breath. 2010;8(2):119-32.

2. Michaud G, Berkowitz DM, Ernst A. Pleuroscopy for Diagnosis and Therapy for Pleural Effusions. Chest [Internet]. 2010;138(5):1242-6. Available from: http://dx.doi.org/10.1378/chest.10-1259

3. Manoharan A, Argaez C. Pleuroscopy for the Diagnosis of Cancer in Patients with Pleural Effusion: A Review of the Diagnostic Accuracy, Safety, Cost-Effectiveness and Guidelines. Can Agency Drugs Technol Heal. 2020;1-43.

4. Alraiyes AH, Dhillon SS, Harris K. Medical Thoracoscopy: Technique and Application Medical Thoracoscopy : Technique and Application. 2016;(April).

5. Loddenkemper R, Lee P, Noppen M, Ma PM. Medical thoracoscopy / pleuroscopy : step by step. Eur Respir Mon. 2010;48:119-32.

6. Mccarty SK, Mcdade KE, Michaud GC. Pleuroscopy: indications and clinical considerations. Shortness of Breath. 2014;3(3):97-101.

7. Ali MS, Light RW, Maldonado F. Pleuroscopy or video-assisted thoracoscopic surgery for exudative pleural effusion : a comparative overview. J Thorac Dis. 2019;11(3):3207-16.

8. Chen RUILIN, Zhang YQ, Wang JUN, Wu HUA, Yang SHUMEI. Diagnostic value of 
medical thoracoscopy for undiagnosed pleural effusions. Exp Ther Med. 2018;16:4590-4.

9. Xu X li, Wang X-G, You W-J. Predictors of survival in non-small cell lung cancer patients with pleural effusion. Thorac Cancer. 2019;

10. Froudarakis M. Research in thoracoscopy (pleuroscopy). Plevra Bul. 2018;7(2):23-9.

11. Wang Z, Xu L, Wu Y, Wang X, Yang Y, Zhang J, et al. Diagnostic value and safety of medical thoracoscopy in tuberculous pleural effusion. Respir Med. 2015;109:1188-92.

12. Lee C, Wang C, Lin S. Diagnosis of Tuberculosis Pleurisy with Three Endoscopic Features via Pleuroscopy. Res Sq. 2020;(June 2nd):1-15.

13. Jo T, Kuse N, Inomata M, Awano N, Tone M, Takada K, et al. Respiratory Medicine Case Reports Efficacy and safety of semi-flexible thoracoscopic cryobiopsy in the diagnosis of elderly tuberculous pleurisy. Respir Med Case Reports [Internet]. 2020;29:101008. Available from: https://doi.org/10.1016/j.rmcr.2020.101008

14. Koul PA. Recurrent Pneumothorax. World Clin Pulm Crit Care Med. 2018;4(2):121-38.

15. Sumalani KK, Rizvi NA, Asghar A. Role of medical Thoracoscopy in the Management of Multiloculated Empyema. BMC Pulm Med. 2018;18(179):1-6. 